\title{
TESTIMONIOS DE LO INDECIBLE. APUNTES PARA PENSAR LA NARRATIVIDAD DEL DOLOR
}

\author{
Testimonies of the unspeakable. Notes to think the narrative of pain
}

\author{
Rosaura Barrios* \\ https://orcid.org/0000-0001-7846-4364 \\ Lidia Schiavoni** \\ https://orcid.org/0000-0002-1932-916X
}

\section{Resumen}

El presente artículo tiene por objetivo tensar algunos planteos en relación a la posibilidad de enunciar testimonios que den cuenta de experiencias atravesadas y/o constituidas por/desde el dolor en dos situaciones comunicativas específicas. Se trata de dos investigaciones de corte etnográfico llevadas a cabo en el AMBA y en la ciudad de Posadas respectivamente. Por un lado, en contextos de escucha de relatos que describan un abuso sexual en población infanto- juvenil cuando interviene la justicia, y por el otro, una experiencia de investigación acción con un grupo de mujeres adultas que realizan acompañamiento y asesoría de casos de violencia sexual y de género autopercibidas como "sobrevivientes", residentes en barrios periurbanos.

$$
<\text { Testimonios }><\text { Violencia de Género }><\text { Comunicación }>
$$

\begin{abstract}
The objective of this article is to stretch some of the statements in relation to the possibility of stating testimonies that account for experiences traversed and / or constituted by / from pain in two specific communicative situations. It is about two ethnographic investigations carried out in the AMBA and in the city of Posadas respectively. On the one hand, in contexts of listening to stories that describe sexual abuse in the child-juvenile population when justice intervenes, and on the other, an action research experience with a group of adult women who provide accompaniment and advice on cases of sexual and gender violence self-perceived as "survivors", living in peri-urban neighborhoods.
\end{abstract}

$$
<\text { Testimony }><\text { Gender Violence }><\text { Comunication }>
$$

Recibido: 29/06/2018

Aceptado: 14/01/2019

\footnotetext{
* Becaria Posdoctoral del CONICET. Docente e investigadora de la Facultad de Humanidades y Ciencias Sociales. IESyH-CONICET/UNaM. Misiones, Argentina. rochabarrios@gmail.com.

** Docente e investigadora de la Facultad de Humanidades y Ciencias Sociales. Secretaría de Investigación y Posgrado. UNaM. Misiones, Argentina.
} 


\section{Introducción}

A raíz del trabajo con las situaciones atravesadas por niñas y niños víctimas de abuso sexual y con las historias de vida de mujeres "sobrevivientes" a múltiples violencias, nos preguntamos sobre las posibilidades de enunciar lo que se presenta como trunco, imposible de ser compartido y codificado en términos testimoniales. Presentamos aquí las tensiones analíticas que se suscitan a la hora de reflexionar a partir de testimonios dolorosos que involucran la violencia sexual, las condiciones de interacción y contextuales que permiten compartir una experiencia dolorosa.

Este problema se deriva de preocupaciones en común de una comunicadora y una antropóloga en búsqueda de respuestas acerca de la posibilidad de narratividad de procesos disruptivos. Partimos de pensar las dificultades que se plantean a la hora de poner en palabras aquello que se presenta (primeramente) como doloroso, abyecto (Kristeva, 1989), lo otro, lo completamente externo que hinca y hace doler el cuerpo y la propia subjetividad. ¿Es posible comunicar el dolor, la angustia, aquello inaprehensible? ¿Cómo es posible convertir en testimonio aquello que se presenta como inverosímil/inadmisible de ser dicho y compartido en términos narrativos? (Aranguren Romero, 2008). Estos debates surgieron al calor de dos investigaciones de las cuales formamos parte, una desarrollada con niños/ niñas y adolescentes que fueron víctimas de abuso sexual en AMBA (Área Metropolitana Buenos Aires) cuyos testimonios fueron utilizados por la justicia ${ }^{1}$; y la otra, con un grupo de mujeres adultas que se reconocen como "sobrevivientes de violencias sexuales y de género" y acompañan y asesoran a víctimas de violencias en dos barrios periféricos de la ciudad de Posadas (Misiones), tratando de facilitar el acceso a instituciones estatales como ser comisarías, defensorías, hospitales².

Discurrimos acerca de las condiciones necesarias o habilitadas para poder simbolizar experiencias traumáticas y dolorosas, increíbles, a veces muy lejanas en el tiempo y otras veces muy difíciles de soportar en el cuerpo. Compartimos aquí nuestras disquisiciones y las escasas respuestas que logramos en este proceso reflexivo.

\section{El problema de testimoniar. Un estado de la cuestión}

La acción de testimoniar involucra varios planteos analíticos: formas de testimoniar, bajo qué condiciones es legítimo hacerlo, quién testimonia, qué hecho es legítimo de ser contado y tenido en cuenta como testimonio. La propuesta reflexiva de este trabajo busca tensar los límites de testimoniar cuando se busca traducir narrativamente experiencias dolorosas como la violación y el abuso sexual.

\footnotetext{
1 Experiencias recuperadas durante el trabajo de campo realizado para una tesis doctoral financiada por CONICET (2012-2017).

2 Se trata del grupo de mujeres Pro-Gen(ero), las mismas perciben un pequeño estipendio en concepto de becas de la Municipalidad que las habilita a realizar este trabajo. Nuestro equipo tanto de investigación como de extensión participó en la capacitación de las mujeres en temas varios como ser anticoncepción, violencia, marcos legales, etc.
} 
De las experiencias del trabajo de campo realizado por ambas investigadoras, surgió la observación de ciertas dificultades para el narrar, sobre todo en población infantojuvenil. Ante la ausencia del relato de violación cometida por alguna persona de la familia, nos preguntamos si es posible compartir esa experiencia dolorosa en clave narrativa.

"La situación de narración en el testimonio envuelve una urgencia de comunicar, un problema de represión, miseria, subalternidad, encarcelamiento, lucha por la supervivencia, implicado en el acto mismo de la narración" (Beverley, 2004, p. 103).

El planteo sobre la posibilidad o imposibilidad de contar una experiencia dolorosa/traumática aparece con fuerza en trabajos que analizan la experiencia de sobrevivientes de distintos conflictos bélicos (Aranguren Romero, 2010-2008), en ocasión de testimoniar crímenes de lesa humanidad de dictaduras militares latinoamericanas (Oberti y Bacci, 2012; Álvarez, 2018), conflictos armados en Colombia (Torres Cuenca, 2017), testimonios históricos sobre masacres indígenas (Beverley, 1992-2004), entre otros. Cuestionar las condiciones simbólicas y materiales que tienen las víctimas para testimoniar nos habilita a reflexionar sobre los quiebres que se constituyen a partir del dolor y cómo se configura el lenguaje en torno a esto.

Julieta Calmels (2007) plantea que la imposibilidad de nombrar actos tan devastadores como el incesto, donde las palabras no encajan en lo que vivencian las víctimas, se debe a que "las palabras estallan", no se puede nombrar como "padre" a un sujeto que viola a su hija, ni ésta puede ser considerada una "hija".

"El incesto es un acto que hace copular la alianza con la filiación, y en esa unión las hace estallar al transgredir las leyes que diferencian a ambos sistemas de relaciones. No elude, ni niega, ni reprime los términos del parentesco, sino que pasa por sobre ellos, los atraviesa, desintegrándolos" (Camels, 2007, p.52).

Ante estas situaciones tan perturbadoras, los sujetos se quedan sin palabras, a lo que se agregan las amenazas sobre el contar y el valor de un "secreto compartido". Estas niñas, nuestras informantes, si se animaron a contar, lo pudieron hacer ya como mujeres adultas con otros elementos interpretativos a su disposición.

Al recuperar la voz de niñas, niños y jóvenes prostituidos, Chejter (2001) señala las dificultades de los protagonistas para construir un relato sobre sus experiencias, la desarticulación de los temas, trozos de una historia que se corta y reaparece en otra situación; referencias en apariencia sueltas que requieren otros tiempos para ser concatenadas, dan cuenta de la dificultad de poner en palabras los sucesos vivenciados. Pues tal como refiere Camblong (2013) "el papel crucial que cumple la narración al tomar la palabra destinada a ordenar el acontecer, experiencias, recuerdos y conferir sentido a la vida misma..." (2013, p. 20) resultaba difícil de lograr a partir de las situaciones que habían y/o estaban vivenciando estos niños, niñas y jóvenes. 
Barrios y Schiavoni. Testimonios de lo indecible. Apuntes para pensar la narratividad del dolor

Obtener un testimonio de una experiencia dolorosa como el incesto puede responder a diferentes circunstancias, desde una niña que reclama protección a una persona adulta que se permite recordar y objetivar en palabras esa experiencia. Diferentes resortes se conjugan para que se logre un testimonio, pero básicamente dos aspectos planteados por Giberti (2014) nos interesan destacar: el contexto y la capacidad de escucha. Con respecto al contexto, son las condiciones socio-históricas y territoriales las que habilitan a que se expresen estas vivencias, desde marcos normativos que protegen a las víctimas hasta espacios sociales comunitarios amigables para contar. La condición de la escucha es otro atributo que debe estar presente para que el testimonio fluya, la capacidad de un interlocutor dispuesto a escuchar, a oír y responder a los enunciados que surjan, respuestas que pueden ser palabras o gestos, pero que dan cuenta de que el otro "comprende" lo que se está diciendo, por más increíble y perturbador que sea el relato; apunta además diferentes indicios para poder establecer la confidencialidad y la verosimilitud del relato.

Las marcas de los hechos narrados que han transcurrido décadas pasadas, no son perceptibles por quienes sólo consideran signos físicos de las violencias, violaciones, abusos e incestos; el valor de estos testimonios "extemporáneos" no radica ya en la posibilidad de castigar al agresor sino fundamentalmente en el efecto reparador que encuentra en los interlocutores alertas y dispuestos a creer en el testimonio. Zanotta Machado (2011) discurre en los efectos que tienen las exigencias de la legislación vigente en Brasil, pero también posible de ser aplicadas en nuestro contexto nacional y local, con respecto al valor de las marcas físicas para dar cuenta de la violencia cotidiana y permanente, y las dificultades que se plantean para darle peso a la palabra de las víctimas frente a los hechos. Nuestros interlocutores, tanto los niños y niñas víctimas de abuso sexual como las mujeres adultas sobrevivientes de violencias, remiten a la casi resignación para "contar algo que no se ve", cuyas marcas son emocionales, afectivas, simbólicas y no necesariamente físicas.

Aranguren Romero (2010 y 2008) plantea los límites de la enunciación y la escucha de testimonios de víctimas de violencia política en Colombia, la investigación social también plantea límites y encrucijadas éticas que son difíciles de sortear a la hora de sistematizar el sufrimiento ajeno. Al igual que Álvarez (2014), da cuenta no sólo de la imposibilidad de enunciar sino de escuchar. Herramienta fundamental en investigación social, ¿Cómo teorizamos el sufrimiento del otro? ¿Cómo sistematizamos? ¿Cómo registramos? ¿Cuáles son los límites de la escucha?

Alejandra Oberti, María Capurro Robles, Susana Skura y Claudia Bacci, problematizan la noción de testimonio y su constitución, "es extraer la experiencia para volverla testimonio" (Oberti, 2014). Estas autoras trabajan con testimonios de mujeres que participaron en grupos armados durante los años 70-80 en la Argentina. Sostienen que es posible identificar un doble uso de los relatos pertenecientes a ex presas políticas en centros clandestinos de detención. En primer lugar, hablan de un uso reparador (intimísimo) para la narradora, y en segundo lugar refieren a un uso instrumental que desde las partes intervinientes en un proceso judicial hacen de los 
testimonios devenidas en pruebas. Estos planteos nos ponen en alerta sobre los modos de decir, de callar, de narrar y de sentir del otro, cómo y dónde se configuran estos discursos. Las sobrevivientes a las que refiere el trabajo de Oberti son mujeres adultas que tuvieron la posibilidad de elaborar sus relatos a partir de experiencias en cautiverio en centros clandestinos de detención. Hablamos de la "renuncia al yo" (Arfuch, 2013) para lograr testimoniar, estos relatos trascienden la particularidad biográfica y ese dolor íntimo/personal pasa a convertirse en una herida histórica ya. Es un eslabón más de una de las memorias colectivas. Estos testimonios ya forman parte de una historia del país, su uso ya es colectivo y sus interpretaciones también.

Torres Cuenca analiza a partir de "la masacre de Trujillo"3 cómo las víctimas articulan su subjetividad, a través del lenguaje, su dolor más íntimo y lo vuelven dolor colectivo, al igual que el estudio que coordina Oberti (2014), transforman esa herida individual en colectiva. La autora incorpora debates éticos a la hora de estudiar estos testimonios y las limitaciones metodológicas que emergen. En esta misma línea, Theidon analiza los testimonios de mujeres que fueron víctimas de violencia sexual por parte de la organización Sendero Luminoso en Perú, a través de una Comisión encargada de recoger testimonios de esos años, pone en tensión la capacidad de agencia que tienen las víctimas al apelar a su derecho al olvido. "Cuando me olvido me siento bien. Recordar (lo que pasó) incluso ahora, me vuelve loca” (2006: p. 82).

Beverley (2004) reflexiona sobre el caso de Rigoberta Menchú e incluye las acusaciones de Stoll sobre los dichos de Rigoberta. "Una narrativa (...) contada en primera persona por un narrador que es también un protagonista o testigo real de los eventos que él o ella cuenta [...] La palabra testimonio traduce literalmente el acto de testificar o de ser testigo en un sentido legal o religioso [...]." (2004, p. 103). Así, el testimonio de Menchú sobre la matanza de su pueblo es cuestionado por no ser testigo directo de esa masacre, hablamos más bien de un testigo "histórico" de lo que tuvo que atravesar su pueblo. El requisito de la presencia física en tiempo real de las y los testimoniantes y la vivencia propia como indispensable para contar pone en jaque el status de testimonio que tuvo la líder indígena y el cual le valió un Premio Nobel.

Este breve recorrido teórico acarrea algunas preguntas: ¿Quiénes están habilitados/as a narrar lo que vivieron? ¿Cómo deben ser esos testimonios/relatos para que sean tenidos en cuenta? ¿Qué requisitos debieran cumplir para que ese relato sea considerado como testimonio?

\section{Sobre el trabajo de campo de nuestra investigaciones}

En el proceso del trabajo de campo con las mujeres adultas no dejó de sorprendernos cómo retazos de historias que se disparaban con una pregunta o un comentario, iban revelando densos episodios vivenciados cuya articulación constituye la experiencia social de un sujeto (Dubet y Martuccelli, 1999). Las digresiones en el

3 "La masacre de Trujillo" refiere a ocho años (1986-1994) en los que bajo un discurso antisubversivo y una visión limitada de las filiaciones partidarias se presentaron asesinatos sistemáticos, ejecuciones extrajudiciales, desapariciones forzadas y torturas de 342 personas en propiedades de narcotraficantes. 
Barrios y Schiavoni. Testimonios de lo indecible. Apuntes para pensar la narratividad del dolor

eje temporal y la superposición de eventos forman parte de este complejo proceso de recuperación de la memoria, de traer al presente tristes sucesos que muchas mujeres consideraban "mejor tenerlos guardados, aunque es difícil..., aparecen en los sueños... y también se meten en tu vida".

La reconstrucción de las historias se fue desatando tanto en entrevistas grupales ${ }^{4}$ como individuales. Se planteaba un tema y según las participantes y sus estados de ánimo, derivaban hacia otros; así por ejemplo de un encuentro fijado para hablar sobre el uso de los métodos anticonceptivos resultó en una mirada sobre las relaciones con las madres. Las entrevistas individuales ${ }^{5}$ permitieron completar huecos en los relatos, pues las instancias grupales, aunque muy fructíferas para recuperar la mirada de ellas mismas sobre las experiencias atravesadas por sus compañeras, constituían espacios poco apropiados para revelar las experiencias "muy guardadas". Las entrevistas individuales se concretaron en las casas particulares y también -en solo un caso- en su lugar de trabajo. El compartir la cotidianeidad de la vida barrial mechada con historias de violencias ocurridas en ese período "reconocidas y toleradas" unas y discutidas otras, como el caso de Marilú (una nena de 13 años violada por su padre quien termina ahorcándose en la celda de la comisaría) o el de Fernanda (niña de 14 años violada y embarazada por un tío a quien en el hospital público se le niega un aborto) permitieron tensar los relatos en su contexto. Y mujeres que habían sufrido experiencias similares, lo pudieron expresar y revisar tanto en las instancias grupales como individuales.

El contacto sostenido con el grupo por más de tres años, posibilitó generar condiciones propicias para contar y compartir, para revisar sus propias historias, lo que "pudieron recordar", lo que las otras les devuelven de sus propias vidas ${ }^{6}$. Los secretos, lo que una se animó a compartir con una o con otras; fueron revelando "lo que antes se guardaba" y fueron aflojando las tensiones internas y descubriendo "el peso de guardar" (Giraud, 2006). Estas mujeres son vecinas desde hace más de quince años; algunas desconocían trágicos episodios de la vida de sus compañeras, el proceso reflexivo que orientó la incorporación de estas mujeres a su condición de promotoras en la prevención de violencias, posibilitó la reconstrucción de sus historias y a nosotros acompañar los cambios en sus modos de ver a las hijas y a los hijos, de repensar cuál era la situación de sus madres, reconciliarse con ellas aún muertas, establecer por qué en un momento dado "mataron al padre"; compartimos sus persistentes esfuerzos y el coraje por intentar cambiar las formas de crianza, replantear las relaciones con sus parejas, etc.

\footnotetext{
${ }^{4}$ Se concertaron encuentros con temas pre-establecidos en los cuales participaron entre 6 a 9 mujeres en los más pequeños y más de 20 mujeres en los concurridos, la duración de estos encuentros oscilaba entre dos y tres horas, según el interés suscitado por el tema. Se abordaron por ejemplo, los cuerpos femeninos y masculinos, el inicio sexual, las relaciones de pareja, la relación entre madres e hijas, las infecciones de transmisión sexual, entre otros.

5 Se acordaban las visitas a realizar en las casas particulares, eligiendo las mujeres según la participación en los encuentros grupales, algunas muy dispuestas a conversar y otras son seria dificultades para abrirse al diálogo. Las entrevistas domiciliarias tuvieron muy diversa duración pues dependían tanto de los temas como de la dinámica del hogar, algunas de casi tres horas y otras de no más de media hora.

6 Diálogo entre Solange y otra compañera del grupo, antigua vecina del barrio: Lucian "Yo nunca pensé que Perro iba a tener mujer, tan parco, distante. Solange: "Sí es parco pero me respeta, yo lo aprecio".
} 
Ritmos variados y encuentros flexibles fue lo que caracterizó la experiencia con mujeres, distinto al trabajo con niños, niñas y adolescentes que por la particularidad del crimen y en contacto con el sistema legal, entraban en un circuito de confección del testimonio monitoreado y escueto. Los tiempos para contar están sujetos a la confección de la prueba judicial ${ }^{7}$ regidos por un circuito legal que debe cumplir, si no puede quedar desestimado todo intento resolutivo. Esto trae consigo dos dificultades para la investigación: que otra persona ajena a la investigación y ajena disciplinarmente oriente la entrevista, que tiene otros objetivos y función; y que nosotras como investigadoras quedemos sujetas a esa lógica judicial que de no contar con una vigilancia aceitada se entran a confundir los sujetos enunciadores en el análisis.

Finalmente, el material que se analizó no fueron los testimonios en sí sino cómo se confeccionan los mismos en esta lógica institucional y cómo "juegan" un rol fundamental en el proceso resolutivo. No hay forma de que la investigadora direccione la recolección de datos, ni modifique los instrumentos de recolección. Debía investigar con los elementos que la justicia habilita a acceder para analizar y esos elementos fueron pensados por una institución con fines específicos y los datos que ellos buscan quizás no sean los mismos que una investigadora social busca. Por este motivo el contenido en sí del testimonio pasó a segundo lugar, lo que estaba a la vista era que había formatos pre establecidos por la justicia para el contar y eran esos formatos a los que quería llegar. ¿Cómo se genera testimonio de abuso sexual en una situación hiper codificada/ regulada para el contar como la cámara gesell? Al final de la investigación pude evidenciar las falencias de este dispositivo y la estrechez para codificar el dolor. En cuanto a las tensiones, no había grietas para los matices, los sentires distintos al daño, para los juegos, los cantos de niñez, para el tiempo prolongado que requiere narrar el dolor. En seis sesiones debían contar qué sucedió y con quién. Esta pauta es la que guía la entrevista en gesell, distinta a las pautas que pueden guiar a una investigadora.

El silencio fue una constante en las narrativas trabajadas en las investigaciones, su decodificación fue un aprendizaje diario en el trabajo de campo. El silencio formó parte de estos relatos, compartidos bajo parámetros y normativas específicas con la justicia mediando y como equipo de apoyo técnico. Ambas situaciones fueron armadas y pensadas para que el relato sea compartido, uno con objetivos de resolución legal y otra como insumo para una investigación. Tanto el trabajo con población infanto-juvenil como con población adulta, el contexto que se pensó y creó para contar la experiencia fue "artificial". Aun así, la pregunta por la ausencia del relato o la dificultad de ponerlo en palabras estuvo presente durante las presentes investigaciones. Se tensionaban dos momentos, la urgencia de contar y aquello que no podía ser contado por lo terrible que significaba para quienes lo sufrían. Nosotras como investigadoras tuvimos que aprender a convivir con los silencios, percatadas de que eran una constante en trabajos que abordan el dolor ajeno. ¿Cómo investigar aquello que no puede ser dicho? ¿O quizás

\footnotetext{
En el caso de la confección de la evaluación psicodiagnóstica (pericia que se analizó en este campo) el relato debe aparecer en el transcurso de seis a diez encuentros, como mucho, con la terapeuta de una hora cada encuentro. A razón de un encuentro por semana, en máximo dos meses la terapeuta debe tener listo el informe para ser entregado al juez competente en la causa.
} 
aceptar que el silencio en sí mismo constituye el medio a través del cual podemos tejer relaciones respetuosas donde hasta las palabras sobran? (Lozonczy, 2008).

En el marco de la investigación con las mujeres adultas, éstas mecharon sus historias a lo largo de toda la investigación incorporando "cuando pudieron" o se sintieron habilitadas, los relatos más duros de situaciones traumáticas. Ellas, como sobrevivientes de distintas violencias ${ }^{8}$ (física, simbólica, sexual, económica) se apropiaron de distintos momentos de la investigación ${ }^{9}$ para contar sus experiencias.

"Yo tuve una violación de mi padre y todo eso que nunca pude superar porque no se lo conté a nadie, él me decía a mí: si vos contás yo voy a venir, te voy a sacar y te voy a matar... entonces yo eso llevaba adentro mío eso, yo después fui creciendo, fui creciendo y fui viendo todas las chicas que entraban [al orfelinato donde vivía] los problemas que tenían, y yo veía que ellas contaban, porque ahí había un grupo de psicólogos y ellos hablaban... y yo nunca me animé porque pensaba que me iban a decir mira vos que fuiste violada por tu papá ...eso era mi temor que me digan". (Promotora J., 62 años, violada por su padre desde los 8 a los 11 años).

La amenaza de muerte que se torna real para esa niña (dicho por ella misma), a la que se agrega la vergüenza del incesto -que no se puede nombrar como tal- en un contexto socio-histórico donde este tipo de experiencias circulaban pero estigmatizaban, hace cinco décadas. A quien pudo relatar el episodio en la infancia, fue su abuela, quien relativizó el suceso al decir "a todas las mujeres nos pasan estas cosas, ya te va a dejar de joder"... [en referencia al padre agresor $]^{10}$. Y efectivamente cuando la niña comenzó a menstruar la internaron un orfanato donde simplemente se consignó que su madre había muerto años atrás y, como vivían en un campo sin escuela cercana, internada allí podría estudiar. Esta mujer es analfabeta, nunca pudo aprender a leer y escribir, "no me entraba en la cabeza, no podía atender lo que decían las maestras". Su condición de víctima de incesto no fue reconocida hasta hace una década, cuando en un contexto singular se reconocieron estos episodios como reales y tremendos; anticipables y evitables. El contexto que hizo posible la enunciación de este testimonio no solo lo constituyó un marco normativo protector sino un espacio comunitario permeable y no estigmatizante ante estos episodios, por desgracia frecuente y recientemente denunciados.

Ahora bien, el rol de víctima, se construye a partir del reconocimiento de otros de la situación de violencia atravesada; las respuestas naturalizadas hacia el incesto, la aceptación y /o resignación de la dominación masculina impidieron que esta niña se

\footnotetext{
8 Esta es una característica que insisten en resaltar de su labor.

9 Vale mencionar que el equipo de investigación intervino no sólo asesorando a las promotoras en materia de salud sexual desarrollando talleres de capacitación en el barrio, sino también como equipo de soporte ante la presencia de casos difíciles de resolver por ellas mismas.

${ }^{10}$ Entrevista realizada por la investigadora a Promotora J., 62 años. 2011.
} 
reconociera como tal, y replegando el dolor transcurrió su vida como joven y adulta hasta lograr "ordenar" su vida a partir de la reiteración del relato (Schiavoni, 2012).

Los relatos de experiencias dolorosas derivan en un reposicionamiento de sus narradores: re-vivir la situación, el proceso exige un esfuerzo de memoria y articulaciones entre sensaciones e información cuya síntesis rescatamos como un testimonio. ¿Cuál es el límite que fijamos como interlocutoras o nos fijan para seguir desgranando las historias? El repliegue del "otro" o nuestra propia resistencia, los efectos no solo se producen en quien hilvana el relato sino también en quien acompaña y estimula ese contar. Los marcos de interpretación teórica se vuelven estrechos a la hora de encuadrar y comprender aquello que se está enunciando:

"[...] la ruptura de las condiciones de posibilidad de la comprensión de hechos de degradación y muerte, la necesidad de hablar, la urgencia de ser escuchado, la emergencia del silencio para preservar la intimidad o el anonimato, el hueco, el vacío, el mismo dolor" (Aranguren Romero, 2008:21). narrativos?

¿Es aprehensible la riqueza de la experiencia? ¿Es posible traducirla en términos

El objetivo de traer ambas investigaciones nos facilita puntas para pensar y dar cuenta de esa incapacidad y ansiedad que tuvimos por nominar y etiquetar en el campo científico. No buscamos los relatos representativos de lo que planteamos aquí, sino ver cómo articulamos y llegamos a los debates sobre testimonio y experiencia. Para este trabajo nos interesa plantear la complejidad que suponen los modos en que esa vivencia, sensaciones corporales y emocionales, se objetivan como experiencia y logra ser enunciada, cómo el lenguaje (y las concesiones que se prestan) configura la experiencia según los estándares disponibles para el compartir (Arfuch, 2013).

Las interacciones sociales dejan huellas en los sujetos, más aún aquéllas que escapan a la cotidianeidad y resultan dolorosas; transformar esas sensaciones que componen la vivencia y poder constituirla como una experiencia, poner en palabras, simbolizar y objetivar esos episodios suponen pasar del orden subjetivo al orden social, el lenguaje como posibilitador de traducir sensaciones individuales en experiencias sociales, comprensible y decodificables por los "otros". La posibilidad de comprender exige previamente la capacidad de escucha y habilitación a la experiencia del que cuenta. La entrevista de investigación como instancia de interacción social, genera un espacio singular en la vida de los sujetos entrevistados, según la empatía lograda y las habilidades del investigador, los informantes pueden capitalizar ese momento como un tiempo privilegiado para reflexionar sobre sus propias vidas, recuperar con una escucha segura sus vivencias. Como señala Bourdieu a "la manera de un partero", la investigadora dispuesta a perseguir la verdad puede improvisar sobre la marcha estrategias que posibiliten el surgimiento de estos testimonios (1993).

Si partimos de esta base para considerar a la narrativa como motor de la experiencia estamos en condiciones de decir que cada contexto comunicativo establece 
Barrios y Schiavoni. Testimonios de lo indecible. Apuntes para pensar la narratividad del dolor

las lógicas y dinámicas del sentir la experiencia traumática para luego enunciarla en términos narrativos: ¿Hasta dónde es posible contar el dolor?

En cuanto a los tiempos, con el grupo de mujeres devinieron sus relatos en modos y tiempos del contar muy distintos al que estamos acostumbradas. Estos relatos fueron tomados-como señalamos antes- en distintas situaciones que se prestaron no necesariamente en entrevista: al finalizar un taller, mientras las mujeres realizaban intervenciones en el barrio, en el contexto de una capacitación. Las situaciones de las que se apropiaron para compartir su dolor no fueron necesariamente las estipuladas por la investigadora. Distinto fue el trabajo con población infanto- juvenil: los testimonios son apurados por la justicia que necesita en un determinado período de tiempo y forma que sea enunciado y escrito en formato de informe aquello que declaró el niño, niñas y/o adolescente.

Si bien excede los objetivos del presente artículo, vale mencionar cómo el cuerpo de las investigadoras pasa a convertirse en el principal instrumento de percepción de la experiencia testimonial de situaciones violentas. No existe grabadora que pueda abarcar el estremecimiento que significa relatar una situación de incesto, más si el cuerpo de la investigadora frente a esas miserias es capaz de aprehender parte de ese dolor, de esa sensación de desamparo y angustia. El ejercicio de la atención somática planteada por Csordas (en Citro, 2011) como un modo de registro que complementa y/o trasciende a las palabras dio sentido a nuestras propias sensaciones, al cansancio y al agobio físico ante el relato del "otro". Sensaciones que formaron parte de esa experiencia narrativa que será insumo para reflexionar. Aparece la empatía no como aquella capacidad de ponerse en el lugar del "otro", sino como aquella capacidad de sentir el lugar de la otra persona en esos momentos. Somos una en comunión.

Investigar sobre las violencias en nuestras sociedades presupone un compromiso no solo con los temas sino fundamentalmente con los protagonistas y testigos de estos hechos. Ferrándiz y Feixa (2004) nos advierten sobre los riesgos y el desgaste que implica abordar estos temas, las dificultades para encontrarle un sentido a tanto sufrimiento no solo de quienes ponen en palabras sus experiencias sino también de quienes se disponen a la escucha de estos relatos.

En cuanto a las características que debe tener un testimonio para que ser considerado, en el sistema penal, el hecho empírico se convierte en el eje narrativo de cualquier relato enunciado con fines resolutivos. La experiencia no aparece con sus matices más sutiles, solo interesa la narración de los hechos en tanto acciones que dejan marcas, directamente perceptibles por terceros, así toda la dimensión de lo sensitivo se pierde o no encuentra donde colarse y que -a diferencia de una situación de encuentro a partir del trabajo de campo- el dispositivo no flexibiliza sus formas para dar lugar. El trabajo de campo en la investigación social garantiza la plasticidad suficiente para adaptarse a las formas del contar de sus participantes. La experiencia narrativa trata de eso, de la posibilidad de acceder a la vivencia del narrar a través de su materialización en los formatos disponibles para hacerlo (Barrios, 2016), el rememorar y su posibilidad de ser compartido sugiere la intervención de formatos disponibles para ese contar de la experiencia. 
Esta experiencia narrativa infantil también involucra a la aprehensión de la investigadora de esa dimensión sensorial posible y sensible de ser compartida, atención somática en términos de Csordas. Los registros se vuelven posibles gracias a su circulación en moldes preexistentes. A diferencia y en comparación con la dinámica del vínculo con las mujeres adultas que dispuso de marcos y tiempos flexibles para el contar, pero con parámetros y fronteras bien definidas, si bien fue pensado como un espacio comunitario e igualitario siempre la "voz autorizada" será la del equipo que organiza esa situación. El tema que las convoca no es casual ni tampoco los tiempos de los talleres y reuniones. La situación comunicativa se flexibiliza pero aún cuenta con parámetros visibles. Entendemos a la misma como "el espacio y el tiempo en el que ocurre la enunciación -el dónde y el cuándo-, el objeto o el tema sobre el que ocurre la enunciación -aquello de lo que se habla- y la actitud de los hablantes frente a lo que ocurre -la valoración”" (Bajtín, 1998, p. 59).

\section{En cuanto a las voces autorizadas}

"La narrativa se encuentra atravesada por relaciones de poder, por dimensiones ideológicas vinculadas con la vida práctica y las grandes esferas de la vida social; simultáneamente, la narratividad se dispone como un dispositivo constitutivo de esas relaciones, un elemento primordial en la legitimación de imaginarios sociales, donde las tensiones pueden soslayarse o complejizarse [...].” (Fernández, 2015: 21)

Sostener que son azarosas las formas que adquieren o las circunstancias en que surgen las narrativas que se convertirán en testimonios es invisibilizar el dispositivo comunicativo y las competencias de los interlocutores que entran en juego para decodificar aquello que se busca enunciar. Contar el dolor propio es de por sí una tarea incómoda, disruptiva, de quiebre subjetivo, comprender los marcos en los que fueron enunciados nos provee de puntas para pensar bajo qué condiciones o en qué condiciones facilitamos, desde las ciencias sociales, un espacio de interacción para que puedan ser contadas.

Ya se atisban ciertas discusiones éticas en relación al trabajo con el dolor del otro y sus formas de testimoniar, Arfuch nos devuelve no solo la responsabilidad ética que supone la escucha del otro, sino someter el cuerpo del otro a sufrir de nuevo la experiencia traumática a través del lenguaje. Decir, contar, es volver a vivir esa experiencia, ponerla en circulación en un escenario social donde se juega no solamente la puesta en forma de la historia personal, sino también su dimensión terapéutica y ética. “(...) por cuanto restaura el circuito de la comunicación -en presencia o en la ausencia que supone la escritura- y permite escuchar, casi corporalmente, con toda su carga significante en términos de responsabilidad por el Otro." (Arfuch, 2013:76)

La responsabilidad de someter al otro a nuestras reglas del juego para enunciar aquello que le causó mucho dolor debe ser tomado con mucha seriedad no sólo ética sino epistémica también. Los usos de los testimonios que hacemos en las 
ciencias sociales tienen otras finalidades que la que tiene en la justicia o en un taller de formación. Entonces, ¿cuáles son las tensiones que suponen el uso de testimonios para la investigación social?

Arfuch sostiene que no existe un sujeto o una vida que el relato vendría a representar sino que ambos son una unidad inteligible y serán un resultado de la narración (2013:75). Ante la dificultad de enunciar el relato de la experiencia del incesto como tal en el relato de las mujeres adultas podemos deducir, según el recorrido teórico que estamos haciendo, que si no hay relato tampoco hay experiencia puesto que ésta se termina de constituir en su relato. Se termina de vivir durante el proceso del narrar. Las psicólogas especialistas en abuso sexual (Barrios, 2016) dejan entrever en cada intervención que contar un abuso es volver a vivir la experiencia del miedo, del dolor, de la angustia, de la muerte (Volnovich, 2006; Múller y López, 2011). Es en ese momento que toda la existencia de ese sujeto tendrá como núcleo narrativo el dolor, saben que están allí para hablar de aquello que les duele. Estas narrativas, incluso las de ficción, dan forma al mundo real, son una matriz para pensar y formular los relatos. Son los aportes de Jerome Bruner (2004) que obligan a pensar a los relatos como moldes de la experiencia, confeccionan la experiencia y la pensamos a partir de ellos, esto obliga a preguntarnos: ¿qué aparece primero: la experiencia o el relato? Porque el narrador, dirá Benjamin:

"Su talento es de poder narrar su vida y su dignidad; la totalidad de su vida. El narrador es el hombre que permite que las suaves llamas de su narración consuman por completo la mecha de su vida" (1986, p.17).

¿Qué relación tiene el narrador con su materia prima que es la vida?, se pregunta. Y es que el narrar involucra a mucha más que la propia voz, Benjamin lo relaciona con un trabajo más bien artesanal, ¿no será, acaso, labor del narrador elaborar la materia prima de la experiencia -la propia y la ajena- de forma sólida, útil y única? (1986, p. 17).

\section{De los moldes para el contar a testimonios para compartir}

Si bien Bacci, Capurro Robles, Oberti y Skura (2014) sostienen que la existencia de relatos surge cuando el contexto se habilita como espacio de escucha, en algunas situaciones de campo es el testimonio quien se impone con todas sus características formativas para dar forma a ese relato. Irrumpe y da forma a aquello amorfo. Vemos en nuestros propios trabajos que el formato es inflexible por momentos. Cuando interviene la justicia, lo hace con sus ritmos, sus lógicas de producción y codificación; cuando lo hacemos en investigación los tiempos del trabajo de campo deben cortarse en algún momento y ser codificado en términos disciplinares. La búsqueda no es azarosa, los marcos teóricos y metodológicos marcan y guían el ritmo de una entrevista que fue pensada y pautada en un inicio. Así también la interpretación de lo que está sucediendo en contexto de entrevista o encuentro, la vigilancia epistemológica (Guber, 2005) codifica aquello que estamos viviendo, con posibilidades de fugas y sensaciones inclasificables sin dudas, pero la escucha siempre parte de supuestos teóricos metodológicos. 
Es así que los modos del contar y de enunciar cobran particular relevancia ya que son ellos quienes imponen una forma (narrativa) a la experiencia (Arfuch, 2013). En estos modos del contar las situaciones comunicativas lo son todo: moldean la experiencia sensorial de acuerdo a las categorías lingüísticas disponibles. Y paradójicamente nuestra mirada busca ver aquello que no se puede decir, que no se puede nombrar, que no se puede compartir, lo más intransferible: ¿Se puede comunicar el dolor? ¿Cómo se cuenta lo incontable? ¿Es posible ponerle palabras a aquello inaprensible, inverosímil? Aquello amorfo que se presenta como incompartible en principio, se vuelve relato y un bien compartible gracias al pasaje de formas (Hall, 1980) de la experiencia traumática. De la vivencia del abuso sexual o violación, a la enunciación de narrativas en determinadas escenas y situaciones comunicativas y su posterior codificación en clave de testimonio de delito sexual para la intervención de la justicia o sensible de ser utilizada como insumo de investigación social.

En definitiva, a lo que tenemos acceso no es a la experiencia de la violencia, ni siquiera al relato en sí sino a la experiencia narrativa de contar ese dolor (Barrios, 2016), bajo las lógicas y dinámicas narrativas que en ese momento habilite el contexto/situación comunicativa. A pesar de esto, vimos la posibilidad de generar otros formatos y ritmos en la experiencia con las mujeres adultas: las tertulias, los encuentros en el barrio entre vecinas de años de co-residencia, donde no circulaban estas historias. Allí podemos advertir la potencia del grupo que logró habilitar un espacio de escucha para esos sucesos que "preferimos olvidar, pero están”, como mencionó en más de una ocasión una de sus integrantes. El valor no será el de la prueba testimonial para el proceso judicial pero sí para la historia local, barrial. Algunas de estas mujeres estigmatizadas por su condición de víctimas de violencia de género y sexual, instituyeron en su escenario cotidiano (el barrio) un ámbito de intercambio con sus luchas y conflictos, donde es posible que se expresen y escuchen relatos muy diversos, de sucesos actuales pero también de historias muy antiguas, muy guardadas.

\section{Algunas notas sobre la ficción}

La ficción narrativa en el testimonio es una preocupación constante no solo para la investigación social sino también para los organismos que regulan y facilitan el acceso a la justicia. El relato será juzgado en términos morales de verdad/mentira en estos contextos. David Stoll en su libro "Me llamo Rigoberta Menchú" (que apareció a fines de 1998) se refirió a la definición de Beverley de testimonio (citado anteriormente), Stoll argumenta que "juzgado por tales definiciones, Me llamo Rigoberta Menchú no pertenece al género del cual es el más famoso ejemplo, porque éste no es el recuento de un testigo presencial como afirma serlo" (1999: p. 242). En realidad, "lo que Stoll es capaz de demostrar es que algunos detalles y no 'la mayor parte' de la historia de Menchú pueden ser lo que él llama 'una invención literaria'" (Beverley, 2004: 103). Aquí aparece uno de los interrogantes más fuertes y controversiales que se generan cuando hablamos de testimonios: la cuestión de la ficción. Entendida por Bruner (2003/2013) [la ficción literaria] "no se refiere a cosa alguna en el mundo, sino que sólo otorga su sentido a 
las cosas. Es justamente ese sentido de las cosas el que hace posible a continuación la referencia a la vida real”. Bruner no hace una distinción ontológica de lo que implica narrar y vivir, más bien sostiene que cuando planteamos que la vida es vivida y luego narrada abrimos una dimensión que es la ficción. La capacidad pre-narrativa es lo que llamamos una vida, dirá Bruner (2006) y si la acción puede ser narrada es debido a que ya está organizada por signos, reglas y normas. La ficción como tal no existe para esta dimensión de análisis, si la vida es comprendida a través de su narración, la ficción se completa en la vida. La ficción "es una dimensión irreducible de la comprensión de sí. Si es cierto que la ficción sólo se completa en la vida y que la vida sólo se comprende a través de las historias que contamos sobre ella, entonces, podemos decir que una vida examinada, en el sentido de la palabra que tomamos prestada al principio a Sócrates, es una vida narrada" (Ricoeur, 2001, p. 20).

Somos relatos y este ser relatos es la acción que va más allá de concebir a los mismos como formas de representarnos, el narrar es la manera en que nos constituimos como sujetos y es por esto que la narrativa como fenómeno comunicacional constituye una ventana para el estudio epistemológico de los fenómenos sociales (Mumby, 1993/1997). Es a través del estudio de narrativas que accedemos a ese universo simbólico que codifica la vida y a su descentramiento a partir de la experiencia dolorosa. El acceso a la experiencia narrativa a través de la forma del testimonio del dolor permite percibir el descentramiento, más allá de no poder nominarlo, esa imposibilidad es precisamente, motivo y causa del quiebre narrativo del continuum. Esa misma imposibilidad es preocupación constante en trabajos como éstos que, lejos de buscar respuestas, buscamos tensar bajo qué condiciones hacemos investigación social.

\section{¿En qué medida es transferible el dolor?}

Las condiciones de registro del sistema judicial toman en consideran aspectos elementales de las experiencias dolorosas, lo necesario para dar curso a una causa pero dejan al margen otros aspectos muy significativos para las víctimas que nosotras como investigadoras logramos percibir/reconocer y que aportan a evidenciar la densidad de esas acciones de violencia y la importancia de que ingresen en la memoria social.

La investigación social incorpora el debate sobre la posibilidad que tenemos (o no) en las ciencias sociales de investigar la experiencia dolorosa. Sin ánimos de desviar la discusión, la pretensión de que es accesible la experiencia en términos esencialistas queda en evidencia que es, por lo menos, difícil. Es el acceso a la experiencia narrativa del dolor lo que articula no sólo la escucha de las investigadoras sino también su análisis y puesta en dimensiones conceptuales. Su pasaje de formas en testimonios de vida traduce bajo sus lógicas su funcionamiento y puesta en circulación. El dolor es comunicable en la medida que disponga de formatos posibles para tal fin, ya la idea de formato nos sitúa en moldes preestablecidos y es incluso difícil de pensar la dimensión corporal, gestual y sensitiva dentro de esta forma. La investigación social supone desgranar esos pasajes de formas (Hall, 1980), identificar las lógicas y reconfigurar -bajo la categoría "experiencia 
narrativa que supera algunos debates sobre la ficción- la vida vivida versus la vida contada y la premisa siempre presente de que somos aquello que contamos.

En términos de quiebres narrativos a raíz de la experiencia traumática y/o dolorosa:

“¿No se notó acaso que la gente volvía enmudecida del campo de batalla? En lugar de retornar más ricos en experiencias comunicables, volvían empobrecidos. Todo aquello que diez años más tarde se vertió en una marea de libros de guerra, nada tenía que ver con experiencias que se transmiten de boca en boca." (Benjamin, 2013: p. 2).

Nos permite Benjamin pensar esta cuestión, se refiere aquí a la experiencia colectiva e individual de las Guerras Mundiales ¿Cómo una experiencia tan rica, fuerte, dolorosa en términos de vivencias sufrió un repliegue total en términos narrativos/ testimoniales? ¿Qué significa que no pueda ser contada la experiencia? Que no pueda ser compartida. Ante esta "ausencia" de la narración cabe preguntarnos también si estamos ante un repliegue de la experiencia en términos vivenciales, ¿duele menos aquello que no es contado? Quizás más cercana en el tiempo pero con similar efecto, nuestra experiencia con la guerra de Malvinas cuyos sobrevivientes pudieron "tomar la palabra" cuando el contexto social les permitió contar la tragedia que vivieron y ellos mismos reconocieron la importancia de sacar a la luz sus vivencias.

Benjamin hace mención a la crisis de la experiencia, y dice que lo que está en crisis no es la vivencia en sí (Erlebnis), sino la experiencia en el sentido de Erfahrung, aquélla que, excede el ámbito personal o privado de la mera vivencia y resulta comunicable adquiriendo de ese modo un carácter colectivo o compartido (1933/1982). En este sentido, Benjamin tampoco separa al lenguaje de la experiencia, ni supone que uno es anterior al otro, sino que el lenguaje es vehículo y dinamizador de ella. Cuando menciona la experiencia de los soldados que volvieron de la guerra, expone en términos de pobreza su incapacidad de poder compartir, justamente, esa experiencia. El autor también refiere al trabajo artesanal del narrador con su materia prima que es la vida:

¿Cómo es ese proceso de semiotizar lo intangible, la experiencia?

El proceso de narrar será constitutivo del sujeto social y para este trabajo el foco estará en uno de sus núcleos, el dolor. Dolor que no se puede olvidar, se repliega pero sigue estando, y actuando en la vida de los sujetos, por ello asumimos nosotras en tanto investigadoras un compromiso ético al trabajar con las condiciones que hacen posible que esa vivencia se transforme en experiencia al ser contada, al pasar del umbral individual al social.

Para cerrar y sólo para abrir hacia otros debates cabe preguntarnos ¿qué sucede con todo aquello que no puede ser narrado?, ¿nuestros silencios son proporcionales al olvido o tienen que ver, más bien, con la negación de contarnos en esos términos? Esto si pensamos que el lenguaje ingresa en la vida a través de enunciados concretos y es a través de enunciados concretos que la vida ingresa en el lenguaje (Bajtín, 2011). 
De los testimonios analizados y sus condiciones de generación, advertimos que poner palabras, dar ingreso al mundo social, fenómenos dislocantes, disruptores, abyectos, es una responsabilidad tremenda para una niña o un niño: hacer evidente el incesto implica mostrar el desorden familiar; contar los abusos sufridos por familiares cercanos pone en crisis la imagen familiar. Entre los argumentos que hicieron difícil el contar no solo el miedo es una constante, la vergüenza es otro argumento. ¿Qué garantías tienen estos niños y niñas que han padecido abusos y/o fueron incestuados? ¿Cuáles han sido las condiciones político- emocionales que hicieron posible recuperar esas vivencias a las mujeres adultas atravesadas por otras situaciones de violencia?

En términos políticos, la última década posibilitó un marco comprensivo y simbólico en el cual este tipo de narraciones tienen cabida y son creídos. Los marcos legales que los posibilitaron (leyes de protección a la infancia y las mujeres) posicionaron en agenda pública, política e investigativa estas problemáticas. La ley nomina, da nombres a las prácticas y a las experiencias deseables y no deseables para una sociedad. Y ése es uno de sus principales aportes, pues las nominaciones pueden ser aceptados o rechazados, pero requieren ser debatidos y el ejercicio del debate es un proceso de reflexión. La simbolización es una instancia previa a la reflexión y ésta es clave para que se produzca un cambio, pues sin reflexión no hay transformación. Como señala Segato "La ley contribuye a ese largo y esforzado propósito de la reflexividad, e instala una nueva, distinta, referencia moral, y quién sabe, un día, ella pueda representar la moralidad dominante" (2003:143). La formulación de las leyes previene a los sujetos de prácticas inmutables pues muestran el movimiento de creación y reformulación de los acuerdos sociales, ponen en vigencia ciertos principios y retiran del escenario otros que han perdido sentido para ese momento histórico. Las leyes son instrumentos que otorgan historicidad a los procesos sociales, desvanecen la idea de un mundo fijo e inalterable, natural, lo transforman en un mundo en disputa, cambiante. "Esa conciencia desnaturalizadora del orden vigente es la única fuerza que lo desestabiliza" (Segato, 2003 , p. 144). La divulgación de los principios legales así como la generación de instancias reflexivas con los funcionarios públicos pueden constituirse en un modesto aporte para "romper la rutina" de la vida social.

"Hacer conscientes ciertos mecanismos que hacen dolorosa e incluso intolerable la vida no significa neutralizarlos; sacar a la luz las contradicciones no significa resolverlas. Empero, por escéptico que uno sea respecto de la eficacia social del mensaje sociológico, no es posible considerar nulo el efecto que puede ejercer al permitir a quienes sufren descubrir la posibilidad de atribuir ese sufrimiento a causas sociales y sentirse así disculpados; y al hacer conocer con amplitud el origen social, colectivamente ocultado, de la desdicha en todas sus formas, incluidas las más íntimas y secretas" (Bourdieu, 1993, p. 559).

Las situaciones de comunicación se vuelven fundamentales para la enunciación de estas experiencias, atentas a pensar cuál será el núcleo narrativo que constituirá a 
esas personas y las posicionará para la enunciación de sus testimonios. Estas fueron algunas puntas para empezar a pensar la complejidad del abordaje de narrativas que representen experiencias dolorosas referidas a la violencia sexual.

\section{Referencias bibliográficas}

Alvarez, V. (2018). "Testimonios sobre la violencia sexual e (im)posibilidades de escucha en el juicio a las juntas". Prácticas de Oficio, 1(IM), 57-64.

Aranguren Romero, J. P. (2008). "El investigador ante lo indecible y lo inenarrable". Revista Nómadas, $\mathrm{N}^{\mathrm{o}} 29$, pp. 20-33.

Aranguren Romero, J. P. (2010). "De un dolor a un saber: cuerpo, sufrimiento y memoria en los límites de la escritura". Papeles del CEIC, pp. 1-27.

Arfuch, L. (2013). Memoria y Autobiografía. Exploraciones en los límites. Buenos Aires: Fondo de Cultura Económica.

Bacci, C., Robles, M., Oberti, A. y Skura, S. (2012). Y nadie quería saber. Relatos sobre violencia contra las mujeres en el terrorismo de Estado en Argentina. Buenos Aires: Memoria Abierta.

Bajtin, M. y V. Voloshinov (1998). ¿Qué es el lenguaje? La construcción de la enunciación. Ensayo sobre Freud. Buenos Aires: Editorial Almagesto.

Barrios, R. (2016). Cuando termine de contar, ¿me voy a seguir acordando de lo que pasó? Análisis de la experiencia narrativa del abuso sexual infantil en clave comunicacional. Tesis de doctorado en Comunicación [No publicada]. Facultad de Periodismo y Comunicación. Universidad Nacional de La Plata.

Benjamin, W. (1982). "Experiencia y pobreza" [1933]. Discursos interrumpidos I. Madrid: Taurus.

Beverley, J. (1992). "La voz del otro. Testimonio, subalternidad y verdad narrativa". Revista de Crítica Literaria Latinoamericana. Año 18, № 36, pp. 7-19.

Beverley, J. (2004) “¿Nuestra Rigoberta? Autoridad cultural y poder de gestión subalterno". En Subalternidad y representación. Debates en teoría cultural. Madrid: Iberoamericana Vervuert, pp. 103-126.

Bourdieu, P. (1993) Comprender en La Miseria del mundo. Madrid: Fondo de Cultura Económica. Bourdieu, P. (1993) Post-scriptum en La Miseria del mundo. Madrid: Fondo de Cultura Económica. Bruner, J. (2003/2013). La fábrica de historias: derecho, literatura, vida. (2a ed.) Buenos Aires: Fondo de Cultura Económica.

Bruner, J. (2004). “Life as Narrative”. Social Reserch, 71(3), pp.691-710.

Calmels, J. (2007) "El incesto como imposible simbólico". En Calmels, J. y Mendez, M. L. El incesto: un síntoma social. Buenos Aires: Editorial Biblos.

Camblong, A. (2013) "Mi vecino Homi Bhabha". La Rivada. No 1, pp. 1-25.

Chejter, S. (2001) La niñez prostituida. Estudio sobre explotación sexual comercial infantil en la argentina. Buenos Aires: Unicef.

Csordas, T. J. (1993) "Modos somáticos de atención”. En Citro, S. (2011). Cuerpos plurales. Antropología de y desde los cuerpos. Buenos Aires: Editorial Biblos. 
Dubet, F. y Martuccelli, D. (1999) ¿En qué sociedad vivimos? Buenos Aires: Editorial Losada. Fernández, F. (2015). "Una experiencia compleja. Reflexiones sobre el relato y la vida cotidiana en la frontera". Continuidades, 1-23.

Ferrandiz, F. y Feixa, C. (2004) "Una mirada antropológica sobre las violencias". Alteridades, enero-julio, año/vol. 14, No 027, pp. 159-174

Garcia, M. (2004). Narración. Semiosis/Memoria. Posadas: Universidad Nacional de Misiones. Editorial Universitaria.

Giberti, E. (2014) Incesto paterno filial. Una visión desde el género. Buenos Aires: Ediciones Noveduc.

Giraud, C. (2006) Acerca del secreto. Buenos Aires: Ed. Biblos.

Guber, R. (2005). El salvaje metropolitano. Reconstrucción del conocimiento social en el trabajo de campo. Buenos Aires: Editorial Paidós. Estudios de Comunicación.

Hall, S. (1980). "Codificar / Decodificar". En Cultura, Media, Lenguaje. Londres: Hutchinson \& Co. The Centre for Contemporary Cultural Studies. Traducción: Silvia Delfino.

Kristeva, J. (1989) Sobre la abyección en Los Poderes de la Perversión. Madrid: Siglo XXI. Losonczy, A. M. (2008) Del enigma recíproco al saber compartido y al silencio. Figuras de la relación etnográfica en de la Etnografía a la Antropología Reflexiva. Buenos Aires: Ediciones del Sol.

Müller, B. y López, C. (2011). Los dibujos en el abuso sexual infantil. Buenos Aires: Maipue. Ituzaingó.

Oberti, A. (2011). Dar cuenta de sí mismas. La casa, las armas y el género. En Género, política y violencia. Vida cotidiana y militancia en las décadas del sesenta y setenta. Tesis Doctoral, Doctorado en Ciencias Sociales. FSoc/UBA: Mimeo, pp. 203-241.

Oberti, A., Bacci, C. (2014). "Testimonio: debates y desafíos desde América Latina. Clepsidra". Revista del Núcleo de Estudios Sobre Memoria (IDES), 1(1), 111.

Ricoeur, P. (2006). "La vida: un relato en busca de narrador". Revista Ágora, № 25(2), pp. 9-22.

Schiavoni, L. (2012) "El difícil papel de las víctimas en situaciones de explotación sexual, incesto y violencia conyugal". En Antropología y Derecho. Publicación del CEDEAD. Año 6, No 9. Posadas.

Segato, R. (2003) Las estructuras elementales de la violencia. Buenos Aires: Ed. Universidad de Quilmes.

Theidon, K. (2006). "Género en transición: sentido común, mujeres y guerra". Cuadernos de Antropología Social, № 24, pp. 69-92.

Torres Cuenca, L. (2017). Narrativas de la memoria: el poder del lenguaje en la construcción de sentido después de una masacre. Memoria y Sociedad, 21(42), 21-37. https://doi.org/10.11144/Javeriana.mys21-42.nmpl

Volnovich, J. (2006) Abuso Sexual en la Infancia 2. Campo de Análisis e intervención. Buenos Aires: Lumen.

Zanotta Machado, L. (2011) "Emociones violentas y familiares correctivos". En Rifiottis, T. y Castelnuovo, N. (comps.) Antropología, violencia y justicia. Buenos Aires: Editorial Antropofagia. 